\title{
WEST INDIES
}

See Barbados; Jamaica; Trinidad and Tobago. 